\title{
LASER-HEATED MICROFURNACE: GAS ANALYSIS AND GRAPHITE MORPHOLOGY
}

\author{
A M Smith ${ }^{1}$ • Bin Yang • Quan Hua • Michael Mann \\ Australian Nuclear Science and Technology Organisation (ANSTO), Lucas Heights, NSW 2234, Australia.
}

\begin{abstract}
We describe progress in developing a novel miniaturized laser-heated "microfurnace” aimed at preparing ultra-small ( $\sim 5 \mathrm{~g}$ ) graphite samples from $\mathrm{CO}_{2}$ (Smith et al. 2006, 2007, 2010). Recent effort has focused on automation of the process using a LabVIEW interface, which has permitted feedback control of the catalyst temperature as the reaction proceeds and the logging of reaction parameters. We trialed a number of different pure iron catalysts as well as $\mathrm{Fe}_{2} \mathrm{O}_{3}($ which is reduced in situ to iron) and discuss the reaction rates. We studied the graphite morphology by scanning electron microscopy (SEM) and found there is a marked difference in graphite morphology with catalyst type. We assessed how each catalyst performs in the cesium sputter ion source of the ANTARES Accelerator Mass Spectrometry (AMS) facility. We utilized a quadrupole mass spectrometer to study the gas composition during the reaction, in order to better understand the underlying chemical reactions for such small samples and to better estimate the overall efficiency of the process. Results show that all $\mathrm{CO}_{2}$ is converted to $\mathrm{CO}$ by reduction on the iron catalyst within a few minutes of applying laser power. The reaction pressure stabilizes after $40 \mathrm{~min}$; however, some $\mathrm{CO}$ is not converted to graphite. The cold trap temperature of $-80^{\circ} \mathrm{C}$ is effective at trapping $\mathrm{H}_{2} \mathrm{O}$, so there is little $\mathrm{CH}_{4}$ production.
\end{abstract}

\section{INTRODUCTION}

Since the advent of radiocarbon measurements, the minimum sample size has been steadily decreasing, from grams of carbon required for radiometric methods to milligrams needed for early accelerator mass spectrometry (AMS) measurements down to the order of just a few micrograms today. The ability to measure the ${ }^{14} \mathrm{C}$ activity of such small samples has opened up diverse new research opportunities.

For AMS, samples are usually converted to $\mathrm{CO}_{2}$ and then to graphite, generally used as the target in cesium sputter ion sources. This process of producing a solid sample is known as graphitization. Gaseous $\mathrm{CO}_{2}$ ion sources have also been developed, which have the appeal of eliminating the graphitization process. However, gas ion sources can introduce problematic issues such as low ion source currents of short duration as well as significant ${ }^{14} \mathrm{C}$ background from the titanium sputter target upon which the $\mathrm{CO}_{2}$ is adsorbed (Xu et al. 2007). Moreover, once solid graphite has been prepared and pressed into a target holder there is less risk of catastrophic sample loss than with a gas ion source. At ANSTO, we have continually refined and improved our conventional graphitization furnaces (Hua et al. 2004), based on reduction over an iron catalyst in an excess of hydrogen, and we can readily prepare samples containing just $10 \mu \mathrm{g}$ of $\mathrm{C}$, or even smaller if needed. In parallel, we have been exploring a new technique for producing solid graphite targets using a miniaturized "microfurnace" (MF) in which the iron catalyst is directly heated by a focused infrared laser beam.

Motivation for improving our ultra-small sample capability at ANSTO stems from an increasing demand from researchers. The MF was initially constructed with the aim of reliably producing $~ 5-$ $\mu \mathrm{g}$ carbon samples derived from $\mathrm{CO}, \mathrm{CO}_{2}$, and $\mathrm{CH}_{4}$ from ice-core bubbles, where sample size is significantly limited; however, there are many other applications that also require microsample AMS capability. Examples of other small sample applications at ANSTO involve measurement of individual foramifera, specific pollen taxa, diatomaceous (C-poor) earth, and DNA.

\footnotetext{
${ }^{1}$ Corresponding author. Email: ams@ansto.gov.au.
}

(C) 2010 by the Arizona Board of Regents on behalf of the University of Arizona Proceedings of the 20th International Radiocarbon Conference, edited by A J T Jull RADIOCARBON, Vol 52, Nr 2-3, 2010, p 769-782 
We report on studies aimed at understanding the underlying chemical reactions and the morphology of the graphite produced using different catalysts in the MF.

\section{MICROFURNACE}

A detailed description of the microfurnace (MF) was given in Smith et al. (2010). Figures 1a and b show the MF insert, which is mostly constructed from stainless steel and has an internal volume of $0.72 \mathrm{~mL}$. Figure 1c shows the furnace insert in position under the lens that focuses the $25 \mathrm{~W}$ (maximum) $805 \mathrm{~nm}$ (infrared) laser through a quartz window directly onto the catalyst, which is contained in a disposable quartz crucible. An infrared thermometer is also focused through the quartz window at a viewing angle of $60^{\circ}$ to monitor the catalyst temperature. Both systems are focused to a spot size of $<1 \mathrm{~mm}$ diameter, and only this localized region in the crucible gets significantly heated during operation. Figure 1d shows the vacuum and gas system. The experimental parameters are recorded and controlled by a computer using a LabVIEW (National Instruments, Inc.) interface.
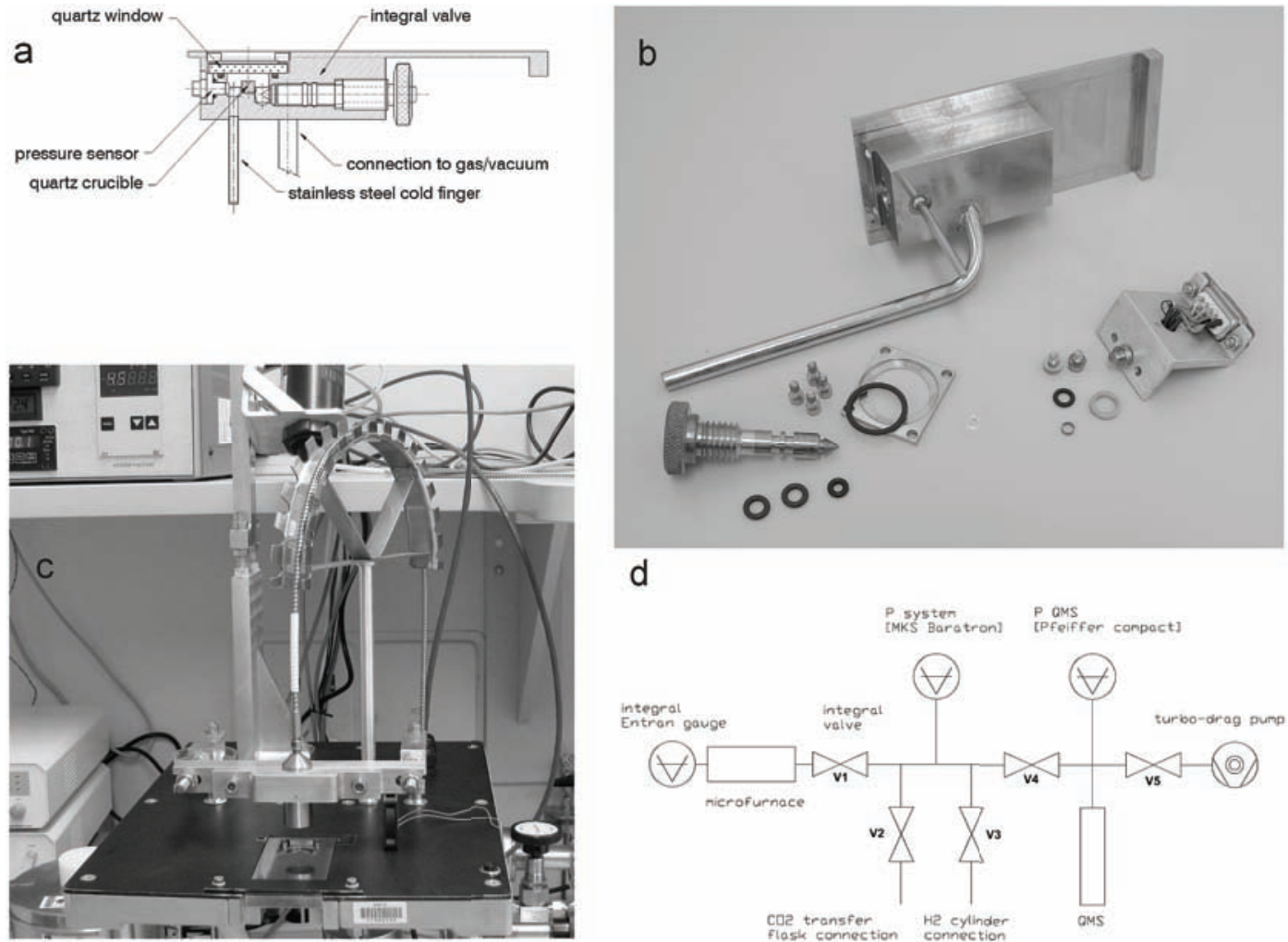

Figure 1 Microfurnace graphitization apparatus: (a) schematic diagram of the microfurnace insert; (b) components of the microfurnace insert; (c) the microfurnace insert in working position. The entire apparatus is enclosed in a light-proof box (removed), interlocked for safe operation of the class-4 laser; (d) schematic diagram of the vacuum and gas system. QMS is a quadrupole mass spectrometer.

The temperature of the cold finger is automatically controlled by a commercial microscope stage heating/cooling system (Linkam) over the range -196 to $20^{\circ} \mathrm{C}$. The stage head was modified by adding a small aluminum block with a hole to accept the stainless steel cold finger and surrounding the cooling head with thermal insulation to improve the cooling efficiency. The advantages of this 
system are that it controls the temperature precisely and can change temperature quickly; however, to do so, it consumes a large amount of liquid nitrogen. For this reason, we are developing another cold finger temperature control system with more modest liquid nitrogen consumption.

Early on, we observed that during graphitization with a fixed laser power, the catalyst temperature increased as the gas pressure decreased. This is a consequence of diminishing convective losses, particularly as the hydrogen, which has a high thermal conductivity, is consumed. Figure 2 shows the catalyst temperature as a function of laser power for various pressures of pure hydrogen. In order to maintain a constant temperature during graphitization, the LabVIEW interface automatically adjusts the laser power according to the current temperature and pressure. Figure 3 shows a typical reaction pressure curve for a $\mathrm{CO}_{2}$ sample containing $50 \mu$ g of carbon with $0.5 \mathrm{mg}$ of Sigma-Aldrich -400 iron catalyst under temperature feedback control. As laser power is applied, the pressure immediately rises because the gas is heated in the vicinity of the catalyst. This is followed by an exponential drop as the reaction proceeds and gas is consumed. The applied laser power is decreased by the LabVIEW system during the reaction in order to maintain a constant temperature of $600{ }^{\circ} \mathrm{C}$. Currently, the system can maintain the catalyst temperature within $\pm 20^{\circ} \mathrm{C}$.

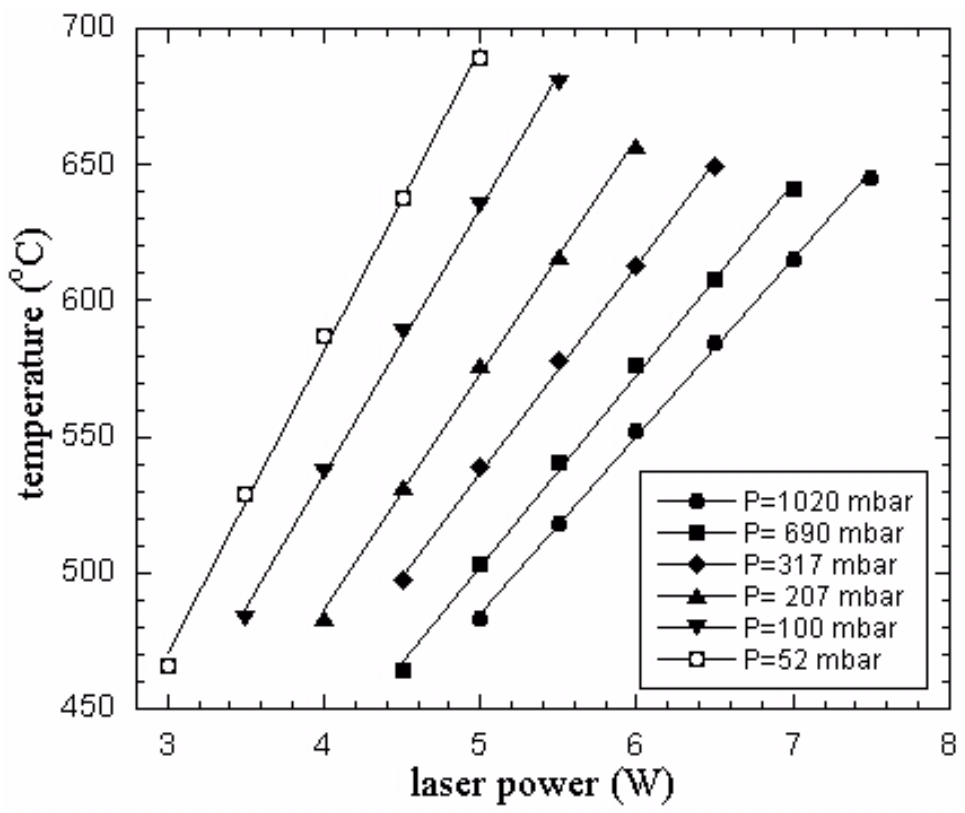

Figure 2 Catalyst temperature as a function of laser power for various pressures of pure hydrogen with $0.5 \mathrm{mg}$ of SA -400 catalyst.

\section{REACTION RATES AND GRAPHITE MORPHOLOGY FOR DIFFERENT CATALYSTS}

The correct choice of catalyst is crucial to optimizing graphite yield, reducing reaction time, and ensuring good target loading and performance in the ion source. As sample size decreases, the inherent carbon in the catalyst becomes an important consideration. Santos et al. (2007a) conducted a survey of 14 iron catalysts and 1 cobalt catalyst. Their selection criteria were the inherent and postreduction catalyst $\mathrm{C}$ content and activity, the graphitization time, and the ion source current and ${ }^{14} \mathrm{C} /$ ${ }^{12} \mathrm{C}$ of prepared ${ }^{14} \mathrm{C}$-depleted material. We have trialed $2 \mathrm{Fe}$ catalysts of the 4 catalysts that passed their selection criterion: Alfa-Aesar -325 (98\% purity, “AA -325”) and Sigma-Aldrich -400 


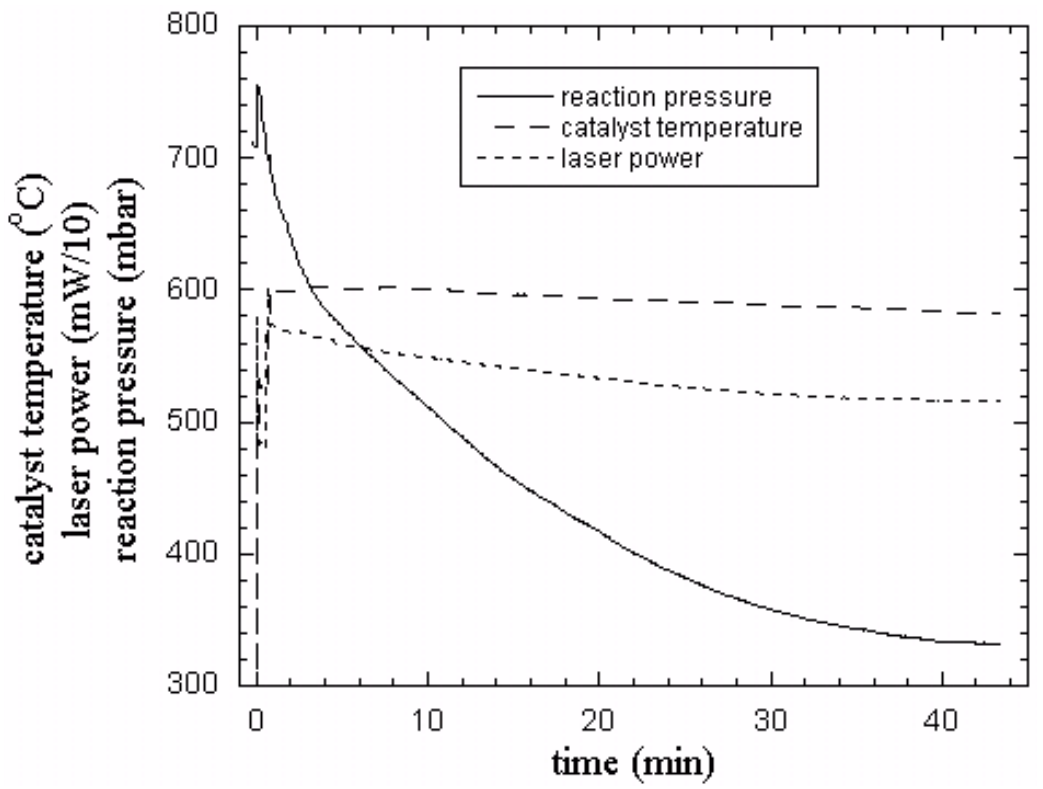

Figure 3 Reaction pressure, catalyst temperature, and laser power during graphitization under normal conditions for a $\mathrm{CO}_{2}$ sample of $50 \mu \mathrm{g}$ of carbon with $0.5 \mathrm{mg}$ of SA -400 under temperature feedback control with a target temperature of $600{ }^{\circ} \mathrm{C}$.

(99.99\% purity, “SA -400”). We also trialed 2 other Fe catalysts: Cerac -325 (99.9\% purity, “Cerac -325 ”), which has been in use in our laboratory for many years (Hua et al. 2004), and Fe nanopowder (25 nm American Elements 99.6\% purity, “Fe nano”). Additionally, we trialed Sigma-Aldrich $\mathrm{Fe}_{2} \mathrm{O}_{3}$ (mesh size unspecified, 99.999\% purity, " $\mathrm{SA} \mathrm{Fe}_{2} \mathrm{O}_{3}$ "), which was reduced to Fe under $\mathrm{H}_{2}$.

The catalyst preferred by Santos et al. (2007b) for producing micro samples is AA -325. Although this catalyst did perform well in terms of yield, reaction time, background, and ion source current, it contained sufficiently high $\mathrm{Li}$ that it was unusable for ${ }^{14} \mathrm{C}$ measurement in the $4+$ charge state: the injected ${ }^{7} \mathrm{Li}_{2}$ - leads to an intense ${ }^{7} \mathrm{Li}^{2+}$ beam in the detector. Of the 2 accelerators at ANSTO, the 2MV STAR accelerator uses the $3+$ charge state, whereas the 10MV ANTARES accelerator (Fink et al. 2004) uses the 4+ charge state; for this reason, AA -325 was not investigated further. The remaining 4 catalysts had acceptable Li content.

For each of the $3 \mathrm{Fe}$ catalysts, we used a fixed amount of $0.5 \mathrm{mg}$ and we used $0.7 \mathrm{mg}$ of $\mathrm{Fe}_{2} \mathrm{O}_{3}$ for an equivalent $0.5 \mathrm{mg}$ of $\mathrm{Fe}$. Initially, each catalyst was reduced at $600{ }^{\circ} \mathrm{C}$ in $700 \mathrm{mbar}$ of high-purity hydrogen for $30 \mathrm{~min}$. Following this, a volume of ${ }^{14} \mathrm{C}$-depleted $\mathrm{CO}_{2}$ gas (cylinder $\mathrm{D} 2$ in Smith et al. 2010), equivalent to $50 \mu \mathrm{g}$ of carbon, was graphitized at $600{ }^{\circ} \mathrm{C}$ with $\mathrm{CO}_{2}: \mathrm{H}_{2} \sim 1: 2.5$ (by volume) for about 40 min (normal experimental conditions). Figure 4 shows the pressure decrease as graphitization proceeded for the 4 catalysts. It is clear that the reaction proceeds at much the same rate for SA $\mathrm{Fe}_{2} \mathrm{O}_{3}$ and SA -400 , whereas Cerac -325 proceeds more slowly and Fe nano reaction proceeds much more rapidly. This is probably due to the smaller particle size and greater area of Fe nano.

The catalysts and graphite were examined with a JEOL JSM6400 SEM provided with a Noran Voyager energy-dispersive spectroscopy system. The samples were firstly coated with $20 \mathrm{~nm}$ of platinum. Figure 5 shows $0.6 \mathrm{mg}$ of SA -400 , still inside the quartz crucible, following graphitization of $\mathrm{CO}_{2}$ gas containing $5 \mu \mathrm{g}$ of carbon at $600{ }^{\circ} \mathrm{C}$. Figure $5 \mathrm{a}$ shows the top side, i.e. the side heated by 


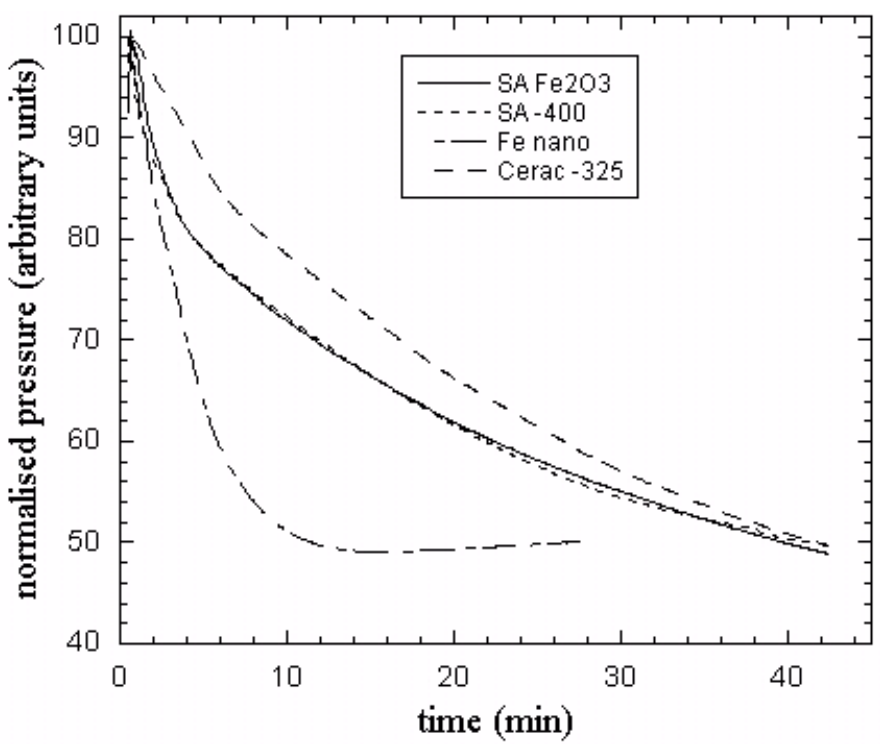

Figure 4 Typical reaction pressure curves for 4 catalysts, $\mathrm{SA}-400$, $\mathrm{SA} \mathrm{Fe} \mathrm{O}_{3}$, Fe nano and Cerac -325 , with a $\mathrm{CO}_{2}$ sample of $50 \mu \mathrm{g}$ of carbon.

the laser. There is a clear difference between catalyst particles that are directly irradiated by the $\sim 0.8$-mm-diameter laser beam and the outermost particles. In the center, the iron particles are fused together forming a porous network (Figure $5 \mathrm{~b}$ ), which indicates that temperature of this area must have approached the melting point of iron $\left(1535^{\circ} \mathrm{C}\right)$. Figure $5 \mathrm{c}$ shows an off-center area where the iron particles have been sintered, rather than melted, together. Graphite tends to form in off-center areas where the temperature is lower.

We observed that the nature of graphite produced on the 4 catalyst types under the conditions described above varied markedly in appearance. Figure 6 shows each of the 4 catalysts following reduction at $600{ }^{\circ} \mathrm{C}$ in $700 \mathrm{mbar}$ of $\mathrm{H}_{2}$ for $30 \mathrm{~min}$ and again following graphitization of $\mathrm{CO}_{2}$ gas containing $50 \mu \mathrm{g}$ of carbon at $600{ }^{\circ} \mathrm{C}$. SA -400 is shown in Figure 6a following reduction and in Figure $6 \mathrm{~b}$ following graphitization. The spherical iron particles are thickly covered by graphite that has a coral-like structure, similar to that observed by Santos et al. (2007a). $\mathrm{SA} \mathrm{Fe}_{2} \mathrm{O}_{3}$ is shown in Figure $6 \mathrm{c}$ following reduction and in Figure $6 \mathrm{~d}$ following graphitization. Here, the graphite seems to have grown in sheets from multiple sites. There was little evidence of filamentous graphite or of carbon nanotubes for these 2 catalysts. Fe nano is shown in Figure 6e following reduction and in Figure $6 \mathrm{f}$ following graphitization. The catalyst is uniformly covered in filamentous graphite. Cerac -325 is shown in Figure 6g following reduction and in Figure 6h following graphitization. The catalyst has a thick growth of filamentous graphite, similar to that observed by Santos et al. (2007a). We have previously noticed that Cerac -325 favors the growth of carbon nanotubes, which, for small samples, appear as dense tangles, patchy amongst uncovered catalyst. High SEM magnification reveals small Fe particles at the tips of many nanotubes.

The iron/graphite samples obtained from SA -400 and $\mathrm{SA} \mathrm{Fe}_{2} \mathrm{O}_{3}$ were similar in appearance and behaved similarly when loaded into 1-mm-diameter rear-loaded target holders (Smith et al. 2010). Using the nomenclature of Santos et al. (2007a), this material could be described as "firm": most of the mixture formed a pellet in the quartz crucible that did not adhere and could be easily broken up. 

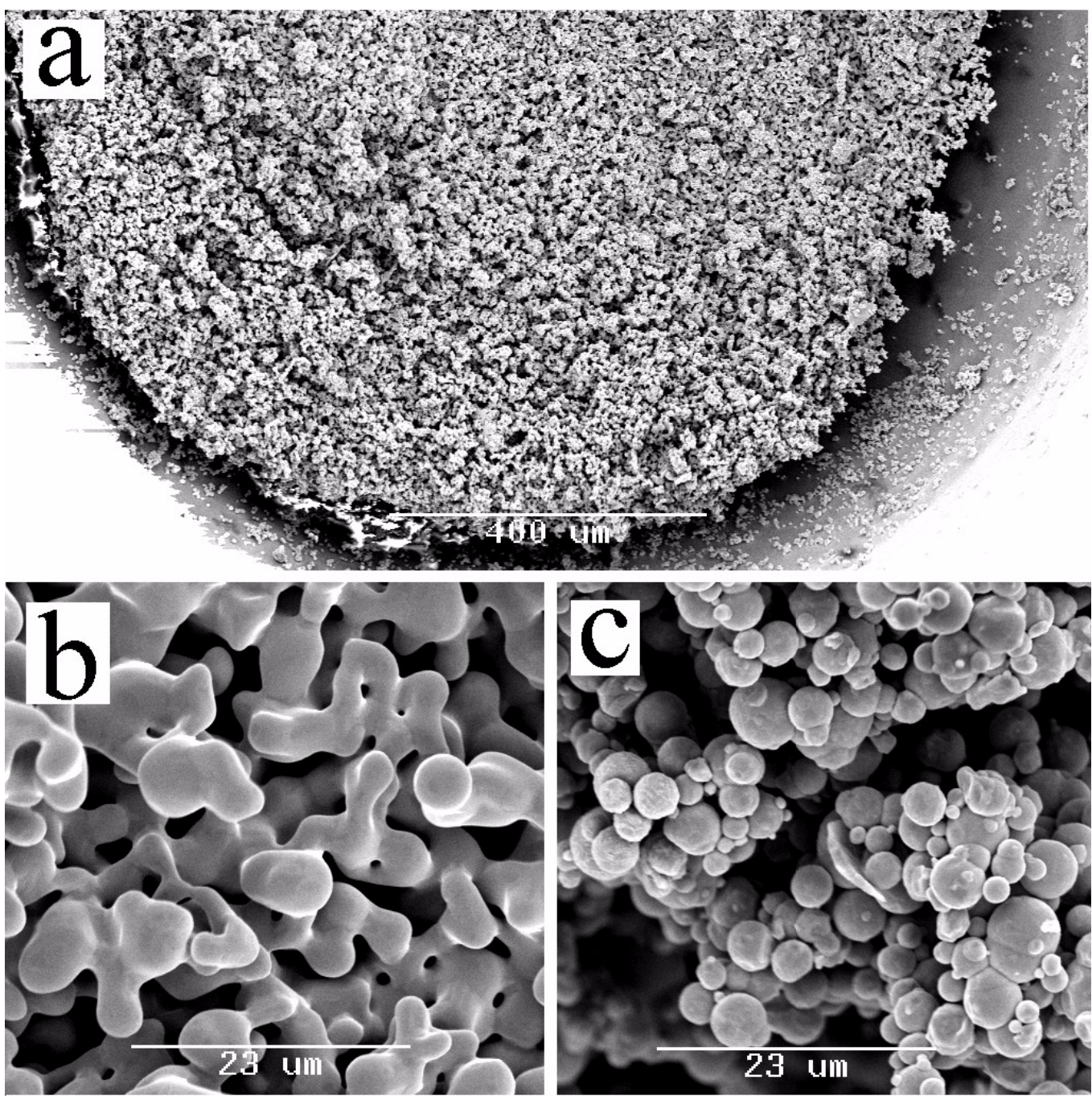

Figure 5 SEM images of $0.6 \mathrm{mg}$ of SA -400 following graphitization of a $\mathrm{CO}_{2}$ sample of $5 \mu \mathrm{g}$ of carbon at $600{ }^{\circ} \mathrm{C}$. The catalyst is still inside the quartz crucible, which has a hemispherical recess of $2 \mathrm{~mm}$ diameter: (a) shows the top side, i.e. the side heated by the laser; (b) shows a region near the center directly beneath the focused laser beam; and (c) shows an off-center region.

The iron/graphite samples obtained from Fe nano was more "fluffy," but this meant that some material was left behind on the quartz crucible. Cerac -325 produced a "firm" material.

\section{REACTION CHEMISTRY}

In order to understand the gas phase chemical reaction and to optimize experimental parameters, gas compositions were obtained with a quadrupole mass spectrometer (QMS) (Balzers Prisma) during graphitization reactions. Additionally, reaction efficiency was evaluated by analyzing the residual gases by QMS following completion of the reaction. 

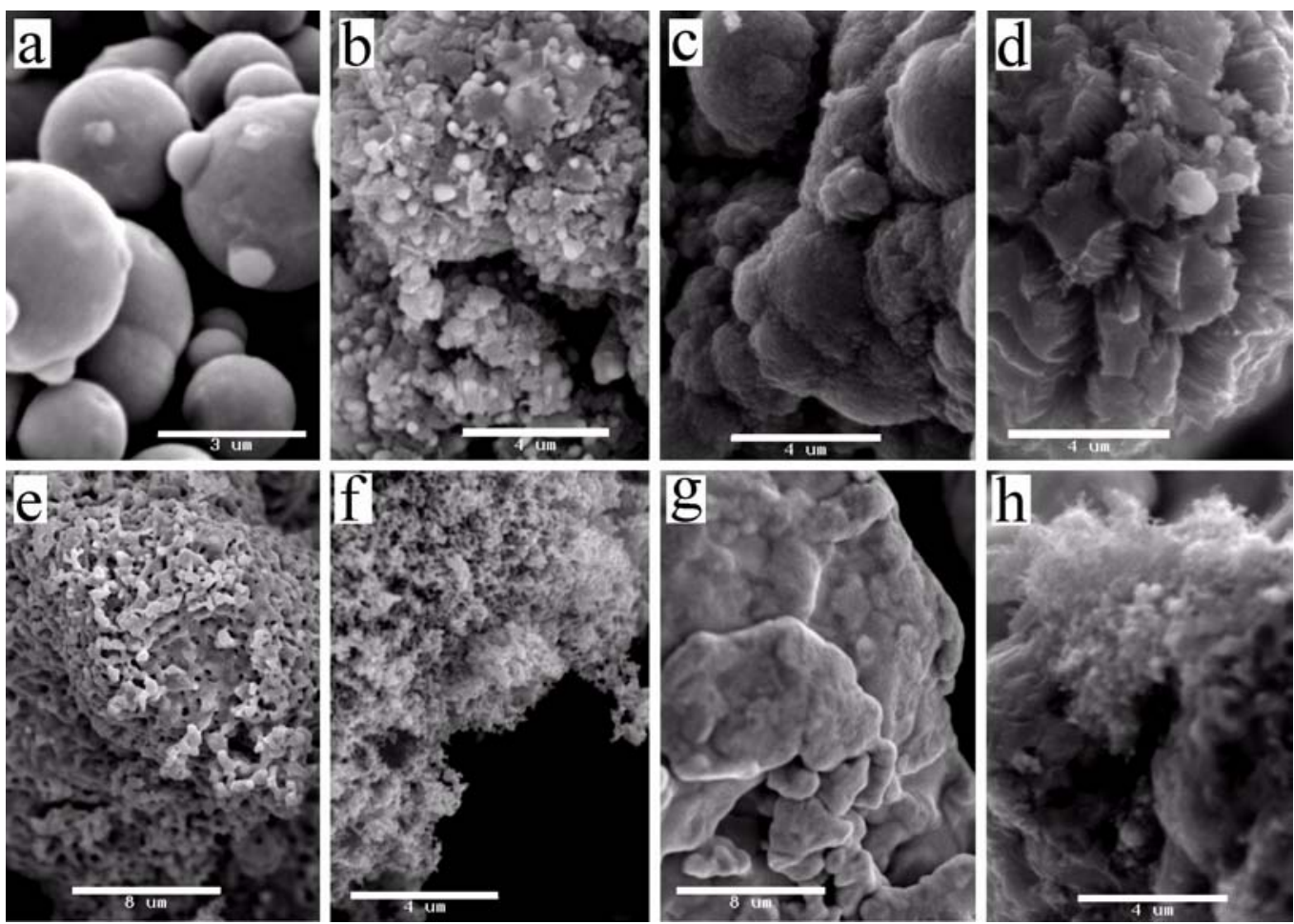

Figure 6 SEM images of catalysts, each $0.5 \mathrm{mg}$ of Fe, following reduction and graphitization of a $\mathrm{CO}_{2}$ sample of $50 \mu \mathrm{g}$ of carbon at $600{ }^{\circ} \mathrm{C}$. SA -400 after reduction (a) and then after graphitization (b); $\mathrm{SA} \mathrm{Fe}_{2} \mathrm{O}_{3}$ after reduction (c) and then after graphitization (d); Fe nano after reduction (e) and then after graphitization (f); and Cerac -325 after reduction (g) and then after graphitization (h).

The QMS has been used previously for studying graphitization reactions in a conventional reactor for 1-mg sized samples (McNichol et al. 1992); however, it is questionable that this work can be scaled down to the 5-50 $\mu \mathrm{g}$ level where the C:Fe ratio differs greatly. QMS is appealing because it can analyze very small quantities of gas and provides reasonable time resolution due to its fast scanning speed (12 s for $48 \mathrm{amu}$ ). On the other hand, it has the disadvantages of ambiguity for mass 28 $\left({ }^{14} \mathrm{~N}_{2}\right.$ or $\left.{ }^{12} \mathrm{C}^{16} \mathrm{O}\right)$ and the production of fragmentation species from the electron ion source (e.g. CO from $\mathrm{CO}_{2}$ ). These disadvantages can be managed with data correction; however, the QMS results can only be considered as semi-quantative.

The QMS was connected as shown in Figure 1d and data were collected in the following way: i) a background spectrum was collected with V1 closed and a vacuum of $\sim 5 \times 10^{-5} \mathrm{mbar}$ at the QMS detector; ii) a data spectrum was collected with the V1 opened slightly to give a pressure of $\sim 2 \times$ $10^{-4}$ mbar at the detector; iii) V1 was closed again to allow the QMS to degas for $4 \mathrm{~min}$; and iv) the above operations were repeated to record a new set of data. This procedure allowed us to record a set of data every $5 \mathrm{~min}$. The gas composition was obtained by subtracting the background spectrum from the data spectrum, as depicted in Figure 7 for a $\mathrm{CO}_{2}$ sample of $50 \mu \mathrm{g}$ of carbon graphitized on $0.5 \mathrm{mg}$ of $\mathrm{Fe}$ of reduced $\mathrm{SA} \mathrm{Fe}_{2} \mathrm{O}_{3}$ at $600{ }^{\circ} \mathrm{C}$ with $\mathrm{CO}_{2}: \mathrm{H}_{2} \sim 1: 2.5$.

Peaks corresponding to $\mathrm{C}, \mathrm{CH}_{4}$, and $\mathrm{CO}$ are evident in Figure 7. These peaks are also present when pure $\mathrm{CO}_{2}$ is admitted with no laser heating and are produced by the QMS electron impact source by 
fragmentation. Figure 8 shows how the production of these species varies with the pressure of pure $\mathrm{CO}_{2}$. It is clear that the observed $\mathrm{CO}$ is produced from breakdown of $\mathrm{CO}_{2}$ since there is no $\mathrm{CO}$ or $\mathrm{N}_{2}$ present to begin with. $\mathrm{H}_{2} \mathrm{O}$, always present in the vacuum system, gives rise to the production of a small amount of $\mathrm{CH}_{4}$.

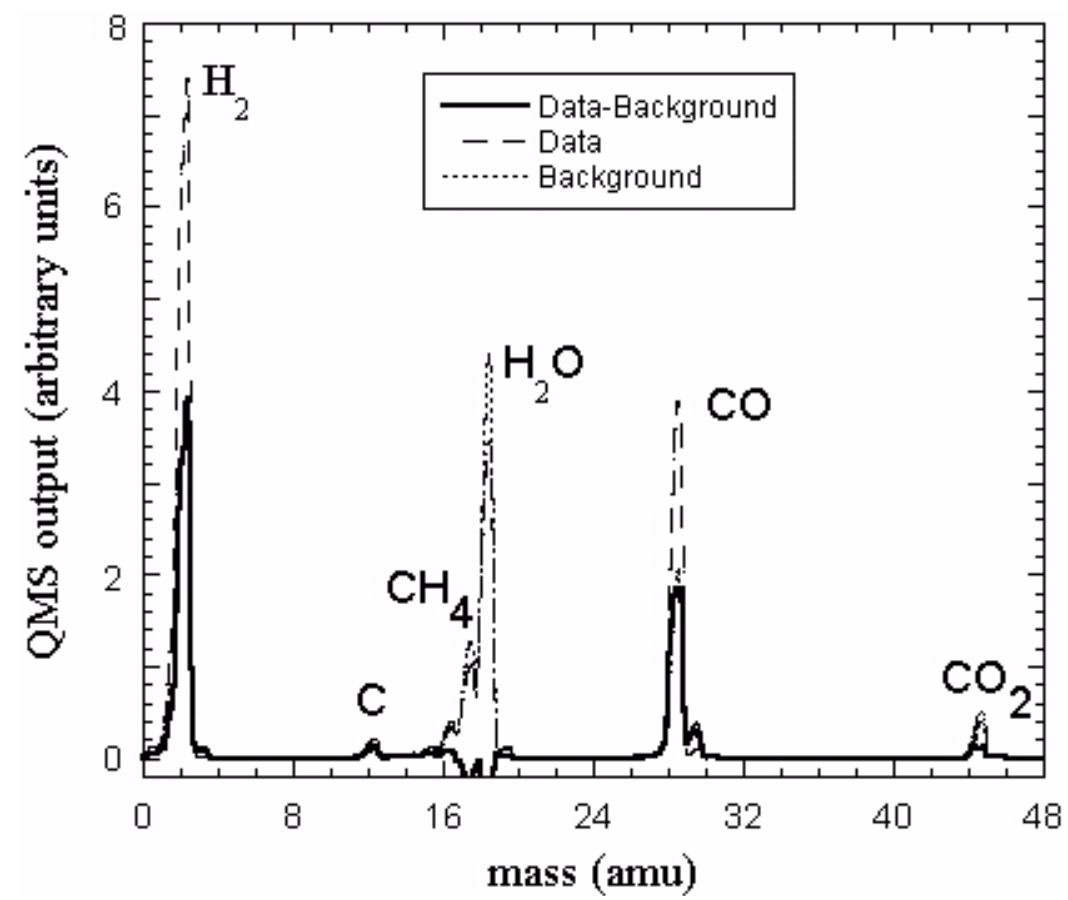

Figure 7 Typical QMS spectrum obtained during graphitization of a $\mathrm{CO}_{2}$ sample of $50 \mu \mathrm{g}$ of carbon $0.5 \mathrm{mg}$ of $\mathrm{Fe}$ of reduced $\mathrm{SA} \mathrm{Fe}_{2} \mathrm{O}_{3}$. The gas composition (solid line) was obtained by subtracting the background spectrum (dashed line) from the data spectrum (broken line).

Figure 9 shows how the gas composition changed during graphitization of a $\mathrm{CO}_{2}$ sample of $50 \mu \mathrm{g} \mathrm{C}$ on $0.5 \mathrm{mg} \mathrm{Fe}$ of reduced $\mathrm{SA} \mathrm{Fe}_{2} \mathrm{O}_{3}$. Individual data was corrected under the assumption that there was no $\mathrm{CO}$ or $\mathrm{CH}_{4}$ before laser heating (i.e. at $t<0$ ) and that observed $\mathrm{CO}$ and $\mathrm{CH}_{4}$ were produced by the QMS from $\mathrm{CO}_{2}, \mathrm{H}_{2}$, and $\mathrm{H}_{2} \mathrm{O}$. Thus, we determine scaling factors to correct measured $\mathrm{CO}$ and $\mathrm{CH}_{4}$ during the reaction. Figure 9 shows that: i) $\mathrm{CO}_{2}$ is rapidly converted to $\mathrm{CO}$ (within minutes) at an Fe temperature of $\sim 60{ }^{\circ} \mathrm{C}$; ii) conversion of $\mathrm{CO}$ to $\mathrm{C}$ is much slower; iii) a small amount of $\mathrm{CH}_{4}$ is also produced; iv) the reaction is effectively completed after $40 \mathrm{~min}$; and v) the conversion efficiency is about $92 \%$ for $50 \mu \mathrm{g}$ of $\mathrm{C}$.

With the benefit of the hindsight afforded by QMS, our earlier method (Smith et al. 2010) of assessing the efficiency by sequentially pumping away $\mathrm{H}_{2}$, then $\mathrm{CO}_{2}$, and then $\mathrm{H}_{2} \mathrm{O}$ was not accurate because the underlying assumption of insignificant $\mathrm{CO}$ or $\mathrm{CH}_{4}$ remaining was wrong. However, it did correctly show that no $\mathrm{CO}_{2}$ remained. There are indications that relative $\mathrm{CH}_{4}$ production may be greater for smaller samples, leading to lower conversion efficiencies because the $\mathrm{CH}_{4}$ remains unreacted. We intend to decrease the temperature for water trapping during the graphitization to ensure that no water is available for $\mathrm{CH}_{4}$ production.

We sometimes observe the reaction pressure begin to slowly rise again at the end of the reaction (after a rapid exponential decrease); this can be seen in Figure 4 for the Fe nano catalyst. This behav- 


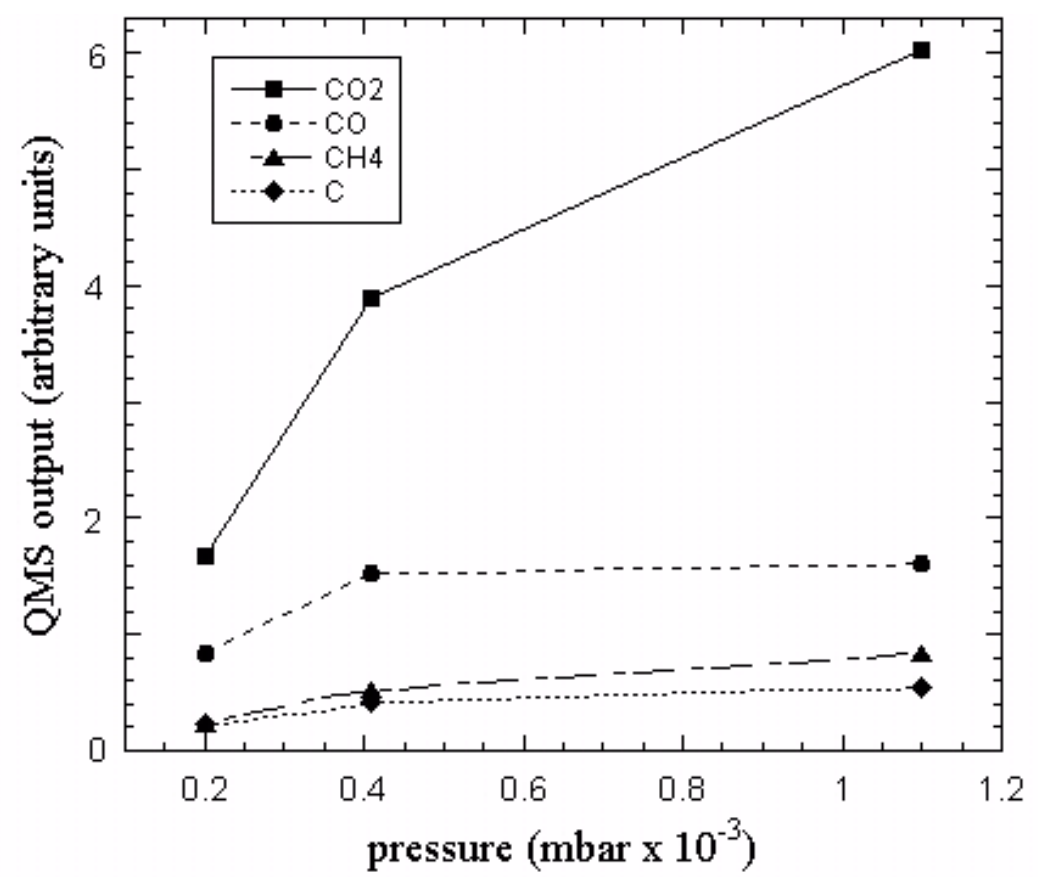

Figure 8 Fragmentation products produced by the QMS from pure $\mathrm{CO}_{2}$ as a function of $\mathrm{CO}_{2}$ pressure.

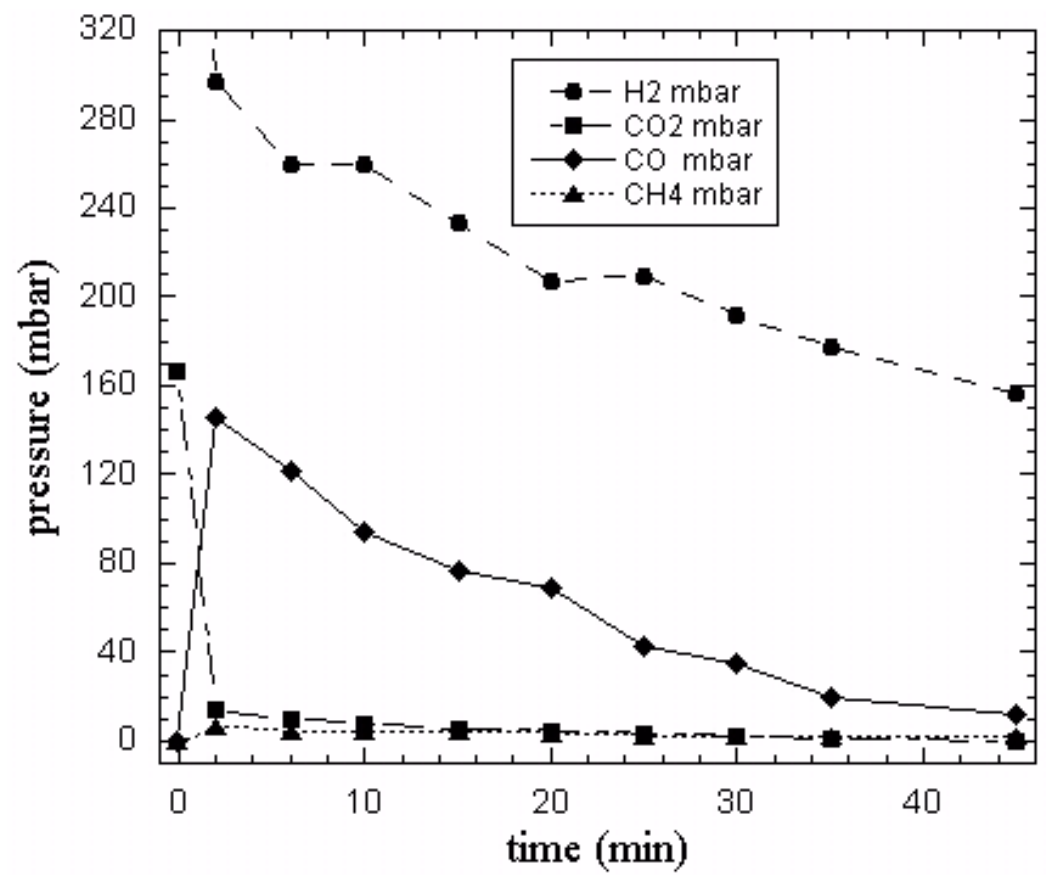

Figure 9 Gas composition during graphitization of $50 \mu \mathrm{g} \mathrm{C}$ on $0.5 \mathrm{mg}$ Fe of reduced $\mathrm{SA} \mathrm{Fe}_{2} \mathrm{O}_{3}$ 
iour has sometimes been observed with the conventional furnaces as well. McNichol et al. (1992) listed 7 reversible reactions that can occur in a graphite reactor, shown in Table 1. Of these reactions, (2), (4), (5), and (6) would lead to a net pressure increase if run in reverse. We suggest that incomplete trapping of $\mathrm{H}_{2} \mathrm{O}$ could be responsible through the underlying reaction $\mathrm{C}+\mathrm{H}_{2} \mathrm{O} \rightarrow \mathrm{CO}+\mathrm{H}_{2}$.

Table 1 Reactions occurring within the graphitization furnace (McNichol et al. 1992). Reaction (3) is relevant for the $\mathrm{Fe} / \mathrm{Zn}$ method.

\begin{tabular}{llll}
\hline $\mathrm{CO}_{2}+\mathrm{H}_{2}$ & $\rightleftarrows$ & $\mathrm{CO}+\mathrm{H}_{2} \mathrm{O}$ & $(1)$ \\
$\mathrm{CO}+\mathrm{H}_{2}$ & $\rightleftarrows$ & $\mathrm{C}(\mathrm{gr})+\mathrm{H}_{2} \mathrm{O}$ & $(2)$ \\
$\mathrm{CO}{ }_{2}+\mathrm{Zn}$ & $\rightleftarrows$ & $\mathrm{CO}+\mathrm{ZnO}$ & $(3)$ \\
$2 \mathrm{CO}$ & $\rightleftarrows$ & $\mathrm{CO}_{2}+\mathrm{C}(\mathrm{gr})$ & $(4)$ \\
$2 \mathrm{CO}+2 \mathrm{H}_{2}$ & $\rightleftarrows$ & $\mathrm{CO}_{2}+\mathrm{CH}_{4}$ & $(5)$ \\
$\mathrm{CO}+3 \mathrm{H}_{2}$ & $\rightleftarrows$ & $\mathrm{H}_{2} \mathrm{O}+\mathrm{CH}_{4}$ & $(6)$ \\
$\mathrm{C}+2 \mathrm{H}_{2}$ & $\rightleftarrows$ & $\mathrm{CH}_{4}$ & $(7)$ \\
\hline
\end{tabular}

\section{ACCELERATOR PERFORMANCE}

Following treatment in the MF at $600{ }^{\circ} \mathrm{C}$ in 700 mbar of high-purity hydrogen for $30 \mathrm{~min}$, the reduced catalysts were loaded in 1-mm-diameter recesses in aluminium target holders, using the rear-loaded pressing technique (Smith et al. 2010). Table 2 summarizes their performance in the ANTARES accelerator; for comparison, empty aluminium target holders produce $0 \mathrm{nA}$ of ${ }^{13} \mathrm{C}^{4+}$ and no ${ }^{14} \mathrm{C}^{4+}$ counts. All of the reduced catalysts contain some inherent carbon and produced a small current. SA $\mathrm{Fe}_{2} \mathrm{O}_{3}$ and SA -400 were similar and produced less current than did Cerac -325 and $\mathrm{Fe}$ nano. Table 2 also shows the ${ }^{14} \mathrm{C}^{4+}$ count rate and the activity of the inherent carbon in pMC; the latter is only approximate because the measured stable current is so low.

Table 2 Carbon current, ${ }^{14} \mathrm{C}$ count rate, and pMC for the 4 different catalysts following reduction at $600{ }^{\circ} \mathrm{C}$ in $700 \mathrm{mbar}$ of hydrogen for $30 \mathrm{~min}$ in the MF.

\begin{tabular}{llllll}
\hline Catalyst type & $\begin{array}{l}\text { Fe mass } \\
(\mathrm{mg})\end{array}$ & $\begin{array}{l}\text { Mean }{ }^{13} \mathrm{C}^{4}+ \\
(\mathrm{nA})\end{array}$ & $\begin{array}{l}\text { Sputter time } \\
\text { (s) }\end{array}$ & $\begin{array}{l}{ }^{14} \mathrm{C} \text { count rate } \\
\text { (counts/min) }\end{array}$ & $\begin{array}{l}\text { pMC } \\
(\%)\end{array}$ \\
\hline $\mathrm{SA}-400$ & $\sim 1$ & 1.1 & 300 & 6.4 & $65.21 \pm 13.43$ \\
$\mathrm{Cerac}-325$ & 0.53 & 0.9 & 580 & 5.3 & $70.19 \pm 10.82$ \\
$\mathrm{Cerac}-325$ & 0.59 & 2.6 & 600 & 11.3 & $52.71 \pm 5.01$ \\
$\mathrm{Fe} \mathrm{nano}$ & 0.49 & 3.8 & 580 & 5.6 & $17.74 \pm 2.97$ \\
$\mathrm{Fe} \mathrm{nano}$ & 0.50 & 3.8 & 580 & 6.7 & $20.88 \pm 2.87$ \\
$\mathrm{SA} \mathrm{Fe} \mathrm{O}_{3}$ & 0.48 & 1.2 & 580 & 2.8 & $27.75 \pm 6.29$ \\
$\mathrm{SA} \mathrm{Fe}_{2} \mathrm{O}_{3}$ & 0.48 & 0.9 & 600 & 1.9 & $26.83 \pm 7.73$ \\
\hline
\end{tabular}

Samples containing a nominal 5 and $50 \mu$ g of carbon were prepared in the MF using ${ }^{14} \mathrm{C}$-depleted $\mathrm{CO}_{2}$ gas (cylinder D2 in Smith et al. 2010, measured activity $0.08 \pm 0.01 \mathrm{pMC}$ ). A fixed amount of each catalyst type containing $\sim 0.5 \mathrm{mg}$ of iron was firstly reduced as described above. Hydrogen was added $\left(\mathrm{CO}_{2}: \mathrm{H}_{2} \sim 1: 2.5\right)$ and the samples were graphitized at $600{ }^{\circ} \mathrm{C}$ for $\sim 40$ min. Table 3 summarizes their performance in the ANTARES accelerator. All samples of commensurate size produced similar currents. It can be seen that the nominal $5 \mu \mathrm{g} C$ samples produce a larger ${ }^{13} \mathrm{C}^{4+}$ current per $\mu \mathrm{g}$ of carbon than do $50 \mu \mathrm{g} C$ samples. The "sputter time" was the duration of the listed measurement; in practice, $5 \mu \mathrm{g} C$ samples produced measurable current for in excess of $20 \mathrm{~min}$. As a typical example, Figure 10 shows the performance of the $5.29 \pm 0.06 \mu \mathrm{g}$ C sample prepared with $\mathrm{SA} \mathrm{Fe}_{2} \mathrm{O}_{3}$ listed in Table 3. This sample was measured for 2 non-contiguous 10 -min periods and could have been measured for longer to improve counting statistics. 
Table 3 Carbon current, current per microgram of $\mathrm{C}$ and pMC for the 4 different catalysts for nominal carbon masses of 5 and $50 \mu \mathrm{g}$. Each sample was prepared using ${ }^{14} \mathrm{C}$-depleted $\mathrm{CO}_{2}$ in an excess of $\mathrm{H}_{2}$ at $600{ }^{\circ} \mathrm{C}$ in the MF.

\begin{tabular}{|c|c|c|c|c|c|c|}
\hline Catalyst type & $\begin{array}{l}\text { Fe mass } \\
(\mathrm{mg})\end{array}$ & $\begin{array}{l}\text { Carbon mass } \\
(\mu \mathrm{g})\end{array}$ & $\begin{array}{l}\text { Mean }{ }^{13} \mathrm{C}^{4+} \\
(\mathrm{nA})\end{array}$ & $\begin{array}{l}\text { Sputter time } \\
\text { (s) }\end{array}$ & $\begin{array}{l}{ }^{13} \mathrm{C}^{4+} / \mu \mathrm{g} \\
(\mathrm{nA} / \mu \mathrm{g})\end{array}$ & $\begin{array}{l}\text { pMC } \\
(\%)\end{array}$ \\
\hline $\mathrm{SA}-400$ & 0.55 & $5.06 \pm 0.05$ & 45 & 560 & 9.0 & $1.40 \pm 0.22$ \\
\hline SA -400 & 0.57 & $5.23 \pm 0.06$ & 63 & 560 & 12.0 & $1.02 \pm 0.15$ \\
\hline SA -400 & 0.59 & $50.87 \pm 0.54$ & 460 & 560 & 9.1 & $0.25 \pm 0.04$ \\
\hline $\mathrm{SA}-400$ & 0.66 & $51.57 \pm 0.56$ & 442 & 540 & 8.6 & $0.28 \pm 0.05$ \\
\hline Cerac -325 & 0.54 & $5.04 \pm 0.05$ & 51 & 1200 & 10.0 & $0.90 \pm 0.14$ \\
\hline Cerac -325 & 0.55 & $5.84 \pm 0.06$ & 78 & 1200 & 13.4 & $0.74 \pm 0.10$ \\
\hline Cerac -325 & 0.51 & $51.75 \pm 0.56$ & 435 & 1200 & 8.4 & $0.24 \pm 0.03$ \\
\hline Cerac -325 & 0.55 & $52.62 \pm 0.57$ & 382 & 1200 & 7.3 & $0.24 \pm 0.05$ \\
\hline Fe nano & 0.53 & $5.07 \pm 0.06$ & 51 & 1200 & 10.0 & $1.61 \pm 0.30$ \\
\hline Fe nano & 0.53 & $5.15 \pm 0.06$ & 46 & 1200 & 9.0 & $6.53 \pm 1.51$ \\
\hline Fe nano & 0.50 & $49.62 \pm 0.59$ & 326 & 1200 & 6.6 & $0.28 \pm 0.03$ \\
\hline Fe nano & 0.55 & $50.61 \pm 0.55$ & 267 & 1200 & 5.3 & $0.26 \pm 0.07$ \\
\hline $\mathrm{SA} \mathrm{Fe} \mathrm{O}_{3}$ & 0.51 & $5.29 \pm 0.06$ & 27 & 1200 & 5.2 & $0.99 \pm 0.15$ \\
\hline $\mathrm{SA} \mathrm{Fe}_{2} \mathrm{O}_{3}$ & 0.45 & $50.40 \pm 0.54$ & 367 & 540 & 7.3 & $0.46 \pm 0.04$ \\
\hline $\mathrm{SA} \mathrm{Fe}_{2} \mathrm{O}_{3}$ & 0.48 & $50.62 \pm 0.56$ & 332 & 1200 & 6.6 & $0.20 \pm 0.06$ \\
\hline $\mathrm{SA} \mathrm{Fe}_{2} \mathrm{O}_{3}$ & 0.49 & $52.14 \pm 0.56$ & 319 & 1200 & 6.1 & $0.21 \pm 0.04$ \\
\hline
\end{tabular}

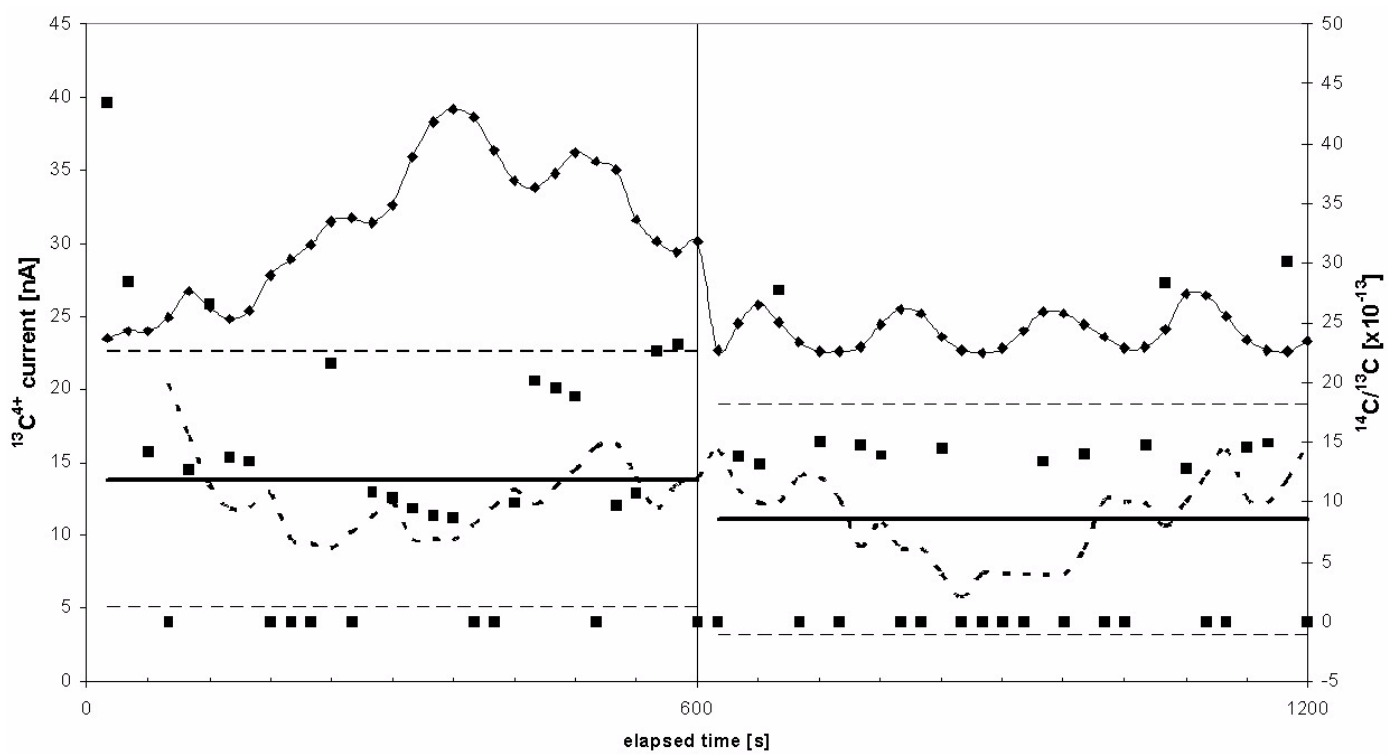

Figure 10 AMS performance of a $5.29 \pm 0.06 \mu \mathrm{g}$ C sample prepared with $\mathrm{SA} \mathrm{Fe}_{2} \mathrm{O}_{3}$; the sample was measured for 2 non-concurrent 10-min periods. Diamonds show the ${ }^{13} \mathrm{C}^{4+}$ current and squares show the ${ }^{14} \mathrm{C} /{ }^{13} \mathrm{C}$ ratio for each $20 \mathrm{~s}$; the dashed curve is the moving averaged ratio. The mean ${ }^{14} \mathrm{C} /{ }^{13} \mathrm{C}$ ratio for each 10 -min block is shown as a solid line; dashed lines are $\pm 1 \mathrm{SD}$.

\section{EXTRANEOUS CARBON FROM MICROFURNACE}

All samples of $\sim 50 \mu \mathrm{g} C$ for all 4 catalysts in Table 3 measured $\sim 0.25$ pMC. There was a larger spread in measured activity for $\sim 5 \mu \mathrm{g}$, with increasing ${ }^{14} \mathrm{C}$ for SA $\mathrm{Fe}_{2} \mathrm{O}_{3}$, Cerac -325 , SA -400 , and 
Fe nano, respectively. To some extent, this may represent the order in which these, and other samples, were prepared in the MF.

We assess the carbon added during graphitization (extraneous carbon) by introducing differentlysized ${ }^{14} \mathrm{C}$-depleted $\mathrm{CO}_{2}$ samples and plotting the measured activity versus $1 / \mathrm{m}$ (Figure 11 ). Ideally, the $\mathrm{CO}_{2}$ used for this assessment should be entirely ${ }^{14} \mathrm{C}$-free. We have found that commercially available $\mathrm{CO}_{2}$, presumably obtained from fossil sources, has lower ${ }^{14} \mathrm{C}$ activity than $\mathrm{CO}_{2}$ prepared in the laboratory, for example, by hydrolysis of large amounts of IAEA C1 marble. Assuming 100 pMC for the activity of extraneous carbon, early in the MF development the mass of extraneous carbon was determined to be $0.15 \mu \mathrm{g}$ (using $0.50 \pm 0.01 \mathrm{pMC} \mathrm{CO}_{2}$ ) and later $0.70 \mu \mathrm{g}$ (using $0.08 \pm 0.01$ $\mathrm{pMC} \mathrm{CO}_{2}$ ) (Smith et al. 2010) by using this technique. The reason for the worsening blank was that the microfurnace had not been cleaned since assembly.

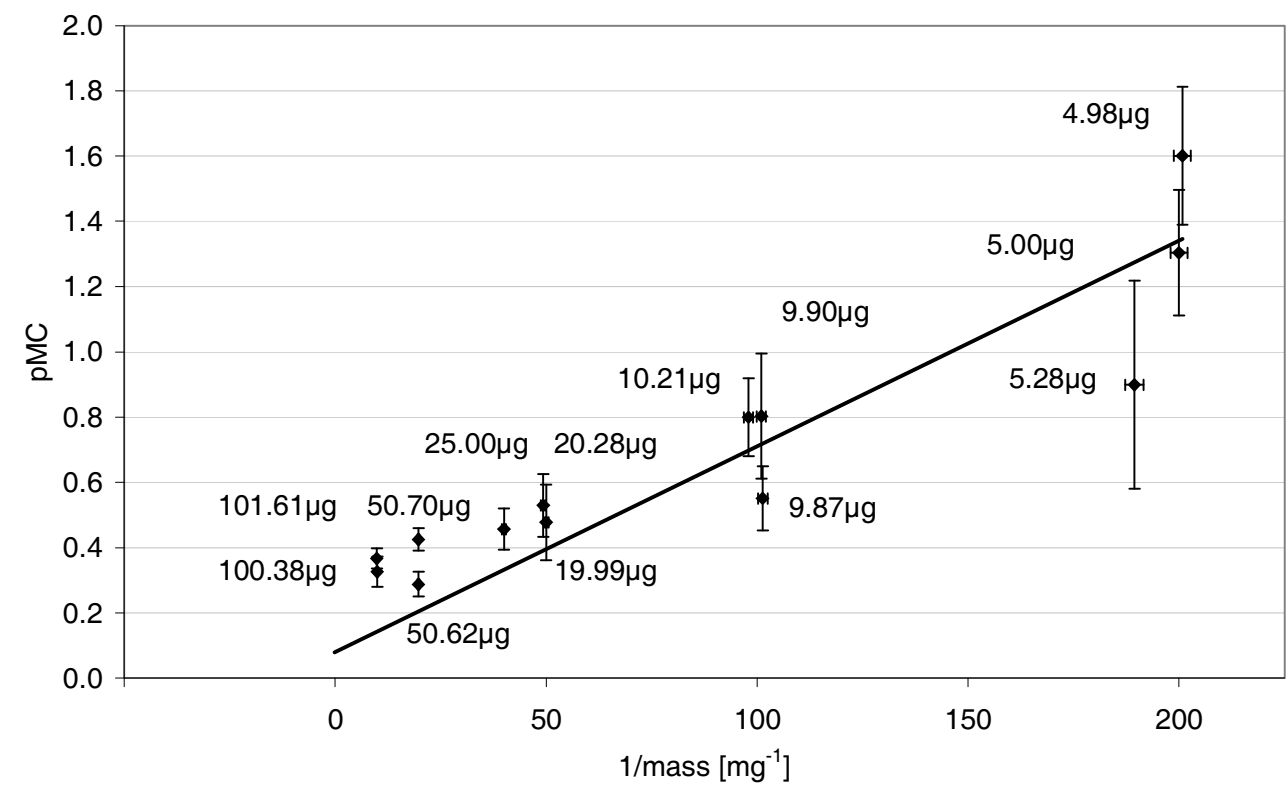

Figure 11 Measured activity plotted against $1 / \mathrm{m}$ for differently sized ${ }^{14} \mathrm{C}$-depleted $\mathrm{CO}_{2}$ samples following graphitization in the microfurnace. Samples were prepared using $\mathrm{Fe}_{2} \mathrm{O}_{3}$ catalyst and $0.08 \pm 0.01 \mathrm{pMC} \mathrm{CO}_{2}$. The sample

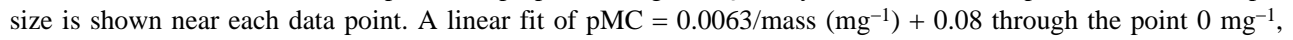
$0.08 \mathrm{pMC}$ gives the amount of extraneous carbon added to be $0.06 \mu \mathrm{g}$ assuming an activity of $100 \mathrm{pMC}$.

In April 2009, the furnace was disassembled and cleaned with acetone and ethanol and air baked at $105^{\circ} \mathrm{C}$ for $24 \mathrm{hr}$ and all Viton O-rings were replaced on re-assembly. A series of differently sized depleted $\mathrm{CO}_{2}$ samples were prepared using $\mathrm{SA} \mathrm{Fe} \mathrm{O}_{3}$ catalyst and $0.08 \pm 0.01 \mathrm{pMC} \mathrm{CO}_{2}$. Figure 10 shows that following cleaning the mass of extraneous carbon was determined to be $0.06 \mu \mathrm{g}$, assuming an activity of 100 pMC. It is possible that this small amount of extraneous carbon is derived from the transfer rig and/or from the transfer flasks used to introduce the sample into the microfurnace, rather than from the furnace itself. It is also possible that there is some slight "memory" from previously prepared non-blank samples. There is also some inherent carbon in the catalyst, as shown in Table 2. All of the samples listed in Tables 2 and 3 were prepared after the MF was cleaned; at present, we do not clean the MF between samples. 


\section{CONCLUSION}

Laser heating of Fe produces a temperature gradient within the catalyst, with graphite forming away from the laser-irradiated area, at least for a target temperature of $600^{\circ} \mathrm{C}$. More work must be undertaken to determine the optimum target temperature and mass of catalyst to produce a more even distribution of graphite within the catalyst.

AA -325 contained sufficiently high $\mathrm{Li}$ that it was unusable for ${ }^{14} \mathrm{C}$ measurement in the $4+$ charge state. All other catalysts have acceptably low intrinsic carbon and $\mathrm{Li}$, with $\mathrm{SA}_{\mathrm{Fe}_{2}} \mathrm{O}_{3}$ and $\mathrm{SA}-400$ having the lowest carbon content. Under our normal experimental conditions, Cerac -325 gives the slowest reaction rate and so is not the preferred catalyst for micro samples. SA -400 and SA $\mathrm{Fe}_{2} \mathrm{O}_{3}$ give very similar reaction rates and Fe nano offers a considerable increase in graphitization rate. In terms of sample pressing and carbon currents, there is little reason to prefer one catalyst over another.

$\mathrm{SA} \mathrm{Fe} \mathrm{O}_{3}$ and $\mathrm{SA}-400$ catalysts produce graphite with similar morphology. Thus, $\mathrm{SA} \mathrm{Fe}_{2} \mathrm{O}_{3}$, which is more readily available in Australia, is a suitable substitute for SA -400 . Cerac -325 and Fe nano both produce filamentous graphite. We plan to explore the use of Fe nano further for the production of micro samples.

QMS analysis with $\mathrm{SA} \mathrm{Fe}_{2} \mathrm{O}_{3}$ has shown that $\mathrm{CO}_{2}$ is very rapidly converted to $\mathrm{CO}$ in the microfurnace. This is partially a consequence of the almost instantaneous heating of the catalyst under the laser, as opposed to the more gradual heating in a conventional tube furnace. QMS demonstrated that the rate-determining step is the conversion of $\mathrm{CO}$ to graphite and that the ultimate reaction efficiency is determined by the amount of $\mathrm{CH}_{4}$ formed.

The microfurnace has proven to be a reliable apparatus for the conversion of $\mathrm{CO}_{2}$ to graphite for sample sizes ranging from 5 to $200 \mu \mathrm{g}$ of carbon with over 120 samples prepared to date. The procedure introduces extraneous carbon at an acceptably low level for the production of ultra-small ${ }^{14} \mathrm{C}$ samples and the samples perform well in the ion source giving acceptable longevity for good measurement statistics.

Future work will focus on further optimizing and automating the process and to develop a second generation device. Objectives are to minimize extraneous carbon, to increase reaction speed (CO conversion) and to maximize efficiency (minimize $\mathrm{CH}_{4}$ ). A systematic study will be undertaken to quantify sample memory effects, which are not expected to be significant.

\section{REFERENCES}

Fink D, Hotchkis M, Hua Q, Jacobsen G, Smith AM, Zoppi U, Child D, Mifsud C, van der Gaast H, Williams A, Williams M. 2004. The ANTARES AMS Facility at ANSTO. Nuclear Instruments and Methods in Physics Research B 223-224:109-15.

Hua Q, Zoppi U, Williams AA, Smith AM. 2004. Smallmass AMS radiocarbon analysis at ANTARES. $\mathrm{Nu}$ clear Instruments and Methods in Physics Research B 223-224:284-92.

McNichol AP, Gagnon AR, Jones GA, Osborne EA. 1992. Illumination of a "black box": analysis of gas composition during graphite target preparation. $R a-$ diocarbon 34(3):321-9.

Santos GM, Mazon M, Southon JR, Rifai S, Moore R. 2007a. Evaluation of iron and cobalt powders as cata- lysts for ${ }^{14} \mathrm{C}$-AMS target preparation. Nuclear Instruments and Methods in Physics Research B 259(1): 308-15.

Santos GM, Southon JR, Griffin S, Beaupre SR, Druffel ERM. 2007b. Ultra small-mass AMS ${ }^{14} \mathrm{C}$ sample preparation and analyses at KCCAMS/UCI Facility. Nuclear Instruments and Methods in Physics Research B 259(1):293-302.

Smith AM, Hua Q, Williams AA, Thorpe KJ. 2006. A novel laser-heated micro-furnace for the preparation of microgram-sized AMS graphite targets. Abstract 55. 19th International Radiocarbon Conference, 3-7 April 2006, Oxford, UK.

Smith AM, Hua Q, Levchenko VA. 2007. New developments in micro-sample ${ }^{14} \mathrm{C}$ AMS at ANSTO. INQUA 
2007 Abstracts. Quaternary International 167-168: 390.

Smith AM, Hua Q, Williams A, Levchenko V, Yang B. 2010. Developments in micro-sample ${ }^{14} \mathrm{C}$ AMS at the ANTARES AMS facility. Nuclear Instruments and
Methods in Physics Research B 268(7-8):919-23. Xu S, Dougans A, Freeman SPHT, Maden C, Loger R. 2007. A gas ion source for radiocarbon measurement at SUERC. Nuclear Instruments and Methods in Physics Research B 259(1):76-82 